\title{
WHO 75 gram OGTT-A single step procedure for screening and diagnosis of gestational diabetes mellitus
}

\author{
Chandana M. Puttaraju*, Manorama Eti
}

Department of Obstetrics \& Gynaecology, Rajarajeshwari Medical College, Bangalore, India

Received: 26 October 2015

Accepted: 18 November 2015

\author{
*Correspondence: \\ Dr. Chandana MP, \\ E-mail: drchandanamp@yahoo.com
}

Copyright: (C) the author(s), publisher and licensee Medip Academy. This is an open-access article distributed under the terms of the Creative Commons Attribution Non-Commercial License, which permits unrestricted non-commercial use, distribution, and reproduction in any medium, provided the original work is properly cited.

\begin{abstract}
Background: Indian women have an eleven fold increased risk of developing glucose intolerance during pregnancy compared to Caucasian women .Universal screening for GDM is essential in India. This study was undertaken to find out a single step procedure which serves both as a screening and a diagnostic tool.

Methods: This study was carried out in a tertiary care teaching institute in Karnataka. 839 pregnant women with gestational age between 24-28 weeks were subjected to 50 gram OGCT and venous blood was drawn after 1 hour. These patients were requested to come after 72 hours on empty stomach for WHO-75 gram OGTT. Fasting and 2 hour blood samples after 75 gram of glucose were drawn.

Results: Amongst the 839 pregnant women who underwent 50 gram OGCT, 136 (16.2\%) women had one hour plasma glucose $>140 \mathrm{mg} / \mathrm{dl}$. Subsequent 75 gram OGTT revealed that only $43(31.62 \%)$ of screen positive patients were diabetic. 93 women who tested positive by 50 gram OGCT were false positive cases (10.58\%). Prevalence of GDM in study population was $6.3 \%$ (53/839). Screening OGCT missed 10 (15.87\%) of gestational diabetes mellitus cases which were picked up by 75 gram WHO OGTT only.

Conclusions: The diagnosis of Gestational Diabetes Mellitus by OGTT based on initial OGCT screening leaves $15.87 \%$ undiagnosed. The two step method of screening OGCT and diagnosing GDM with subsequent OGTT is tedious and not economical. Instead a single step WHO 75 gram fasting OGTT with 2 hour PPG $\geq 140 \mathrm{mg} / \mathrm{dl}$ is simple and precise.
\end{abstract}

Keywords: GDM, OGCT, OGTT

\section{INTRODUCTION}

India is being recognized as "The Diabetes Capital of the World". Diabetes is a major health problem in India with prevalence rates between $4.6 \%$ and $14 \%$ in urban areas, and $1.7 \%$ and $13.2 \%$ in rural areas respectively. India has a an estimated 62 million people with Type 2 Diabetes mellitus; this number is expected to go up to 79.4 million by $2025 .{ }^{1}$ In parallel with increased diabetes prevalence, there is a rise in the prevalence of gestational diabetes mellitus.

Gestational Diabetes Mellitus is defined as carbohydrate intolerance of variable severity with recognition or onset during pregnancy, irrespective of the treatment with insulin. ${ }^{2}$ 
The prevalence of Gestational diabetes mellitus has been reported to range from $3.8 \%$ in $\mathrm{Kashmir}^{3}$ to $41 \%$ in Lucknow. ${ }^{4}$

\section{Impact of GDM}

Women with a history of GDM are at increased risk of future diabetes. ${ }^{5}$

Children born to mothers with uncontrolled diabetes, either pre-gestational or gestational in origin are four to eight times more likely to develop diabetes in later life as compared to their siblings born to the same parents in a non-GDM pregnancy. ${ }^{6}$

Increasing maternal carbohydrate intolerance in pregnant women without GDM is associated with a graded increase in adverse maternal \& foetal outcomes. ${ }^{7}$

\section{Need for screening}

Universal screening is essential in Indian women, as they have an eleven fold increased risk of developing glucose intolerance during pregnancy. ${ }^{8}$

ADA recommends two step methods for screening and diagnosis of gestational diabetes in selective population. Compared to Selective screening, Universal screening for GDM detects more cases and improves maternal and foetal prognosis. ${ }^{9}$

Treatment of Gestational diabetes mellitus, as defined by WHO criteria has reduced serious perinatal morbidity and improved the woman's health related quality of life. ${ }^{10,11}$

This study was undertaken to devise a simplified, economical; single screening and diagnostic test for Gestational diabetes mellitus acceptable in the Indian context.

\section{METHODS}

This study was carried out in a tertiary care teaching institute in Karnataka from November 2007 to October 2009. Pregnant women with gestational age between 24 28 weeks were enrolled in this study. All women were informed about the nature of the study and informed consent taken.

A total of 839 pregnant women underwent detailed clinical examination, irrespective of presence or absence of risk factors. Details of family history of diabetes, history of previous pregnancies, and the socio-economic status were obtained. Blood pressure measurement and the body mass index were recorded.

Initially, pregnant women were subjected to 50 gram OGCT. Fifty gram of glucose was dissolved in $200 \mathrm{ml}$ of water and the patient was asked to drink it over a five minute period, irrespective of time of the day and her last meal. After 1 hour of time of ingestion of glucose, venous blood was drawn. If blood sugar was $\geq 140 \mathrm{mg} / \mathrm{dl}$, the screening was considered as positive. The plasma glucose was estimated by glucose oxidation and per-oxidation (GOD-POD) method by Eco-Pak glucose kit.

All 839 women were requested to have their regular diet for three days and return after observing overnight fast of 8-12 hours for the 75 gram oral glucose tolerance test (OGTT) recommended by WHO. Blood sample was drawn in the fasting state and 2 hours after ingestion of 75 gram glucose. A pregnant woman was diagnosed with Gestational Diabetes Mellitus if the Fasting plasma glucose $\geq 126 \mathrm{mg} / \mathrm{dl}$, and/or 2 hours plasma glucose $>140$ $\mathrm{mg} / \mathrm{dl}$.

\section{Statistical analysis}

Descriptive and inferential statistical analysis has been carried out in the present study.

The Statistical software namely SAS 9.2, SPSS 15.0, Stata 10.1, MedCalc 9.0.1, Systat 12.0 and R environment ver.2.11.1 were used for the analysis of the data and Microsoft word and Excel have been used to generate graphs, tables etc.

\section{RESULTS}

Eight hundred and thirty nine pregnant women were enrolled in our study at a tertiary care teaching institute in Karnataka.

Prevalence of GDM in Study population was $6.3 \%$ $(53 / 839)$ as shown in Figure 1.

\section{Prevalence of GDM}

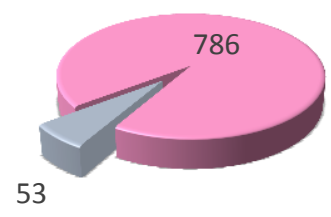

\section{$\square \mathrm{GDM}$}

$\square$ Non Diabetic

\section{Figure 1: Prevalence of GDM}

Table 1 shows that $16.2 \%$ (136/839) of study population had positive screening for 50 gram OGCT. Rest 703 patients were screen negative.

$31.62 \%$ (43/136) of OGCT screen positive patients were diagnosed with gestational diabetes mellitus.

93 cases were diagnosed false positive $(10.58 \%)$ by 50 gram oral glucose challenge test. 
Table 1: Results of 50 gram OGCT

\begin{tabular}{|lll|}
\hline & \multicolumn{2}{l|}{ Results of 50 gram OGCT } \\
\hline $\begin{array}{l}\text { Blood sugar } \\
(\mathbf{m g} / \mathbf{d l})\end{array}$ & No. of patients & $\%$ \\
\hline$<\mathbf{1 4 0}$ & 703 & 83.8 \\
\hline$\geq \mathbf{1 4 0}$ & 136 & 16.2 \\
\hline Total & 839 & 100.0 \\
\hline
\end{tabular}

Table 2 and Figure 2 shows that 10 out of 53 Gestational Diabetes cases were diagnosed by 75 gram WHO OGTT method only, which was missed by 50 gram OGCT screening.

Table 2: Comparison between 50 gram OGCT and 75 gram WHO OGTT

\begin{tabular}{|c|c|c|c|}
\hline \multirow{3}{*}{$\begin{array}{l}\text { OGCT } \\
\text { 50 Gram }\end{array}$} & \multicolumn{3}{|c|}{$\begin{array}{l}\text { Comparison between } 50 \text { gram OGCT } \\
\text { and } 75 \text { gram WHO OGTT }\end{array}$} \\
\hline & \multicolumn{2}{|c|}{ WHO 75gram OGTT } & \multirow{2}{*}{ Total } \\
\hline & GDM Present & GDM Absent & \\
\hline Positive & 43 & 93 & 136 \\
\hline Negative & 10 & 693 & 703 \\
\hline Total & 53 & 786 & 839 \\
\hline
\end{tabular}

WHO: World Health Organisation; OGTT: Oral Glucose Tolerance Test; OGCT-Oral Glucose Challenge Test

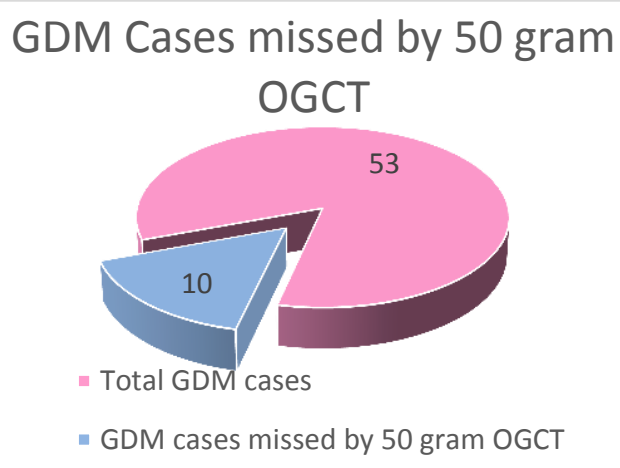

Figure 2: GDM cases missed by 50 gram OGCT

OGCT-50 gram had a sensitivity of $84.12 \%$.The false negative rate of 50 gram OGCT was $15.87 \%$. The predictive value of a positive test was $36.30 \%$ only as shown in Table 3.

\section{DISCUSSION}

GDM not only influences immediate maternal (Preeclampsia, Stillbirths, Macrosomia, PPH, Shoulder dystocia, Caesarean section) and neonatal outcomes
(Hypoglycaemia, Hyperbilirubinemia, respiratory distress), but also increases the risk of future Type 2 diabetes in mother as well as her offspring.

Table 3: Parameters of 50 gram OGCT

\begin{tabular}{|lll|}
\hline & Parameters of 50gram OGCT & Percentage \\
\hline $\mathbf{1}$ & Sensitivity & $\mathbf{8 4 . 1 2 \%}$ \\
\hline $\mathbf{2}$ & Specificity & $\mathbf{8 9 . 4 1 \%}$ \\
\hline $\mathbf{4}$ & Predictive value of a Positive test & $\mathbf{3 6 . 3 0 \%}$ \\
\hline $\mathbf{5}$ & Predictive value of a Negative test & $\mathbf{9 8 . 7 4 \%}$ \\
\hline $\mathbf{6}$ & Percentage of false negatives & $\mathbf{1 5 . 8 7 \%}$ \\
\hline
\end{tabular}

It is essential to screen \& diagnose GDM so as to prevent both the short term and long term implications on the mother and her offspring.

Universal screening is essential in Indian women, as they have an eleven fold increased risk of developing glucose intolerance during pregnancy. ${ }^{8}$ The Asian Indian Phenotype refers to unique clinical \& biochemical abnormalities in Indians which includes increased insulin resistance, greater abdominal adiposity, and a higher waist circumference. This phenotype makes Indians more prone to diabetes. ${ }^{12}$

Apart from ethnicity, high prevalence rate of GDM in Indian population is due to trending towards older maternal age, decrease in physical activity, adoption of modern lifestyle, and increasing prevalence of obesity and diabetes. ${ }^{13}$

\section{$O G C T$}

Pregnant women with gestational age between 24-28 weeks enrolled in our study were subjected to both 50 gram OGCT and WHO 75 gram OGTT.

The timing of glucose tolerance testing during pregnancy is critical, because delayed diagnosis increases the duration of deranged maternal metabolism and accelerated foetal growth. ${ }^{12}$

Insulin is detectable in the foetal pancreas as early as 9 weeks after conception. ${ }^{14}$ The recent concept is to screen for GDM in the first trimester itself as the foetal beta cells recognizes and responds to maternal hyperglycaemia. ${ }^{15}$ If results are negative, tests are to be repeated at 24 to 28 weeks of gestation. This time window is selected because insulin resistance increases as third trimester progresses and early testing may miss some patients who later develop carbohydrate intolerance. $^{12}$

In our study, Screening OGCT had a sensitivity of $84 \%$ and specificity of $89.41 \%$; and missed $15.87 \%$ of the GDM cases which is comparable to results of Huynh $\mathrm{J}$ et al. 
Huynh $\mathrm{J}$ et $\mathrm{al}^{16}$ found that Screening OGCT has a sensitivity of $83 \%$, specificity of $75 \%$ and would miss $17 \%$ of the cases and concluded that OGTT alone is the best procedure without prior GCT.

The false positive rate of OGCT was as high as $10.58 \%$ in our study. This imposed extra testing burden and raised undue concern in these patients. This is comparable to $14.5 \%$ false positive rate of OGCT in study by Das et al. $^{17}$

Predictive value of a Positive and Negative OGCT was $36.30 \%$ and $98.74 \%$ respectively in our study, which is comparable to $24.5 \%$ and $90.1 \%$ respectively in study by Seshiah et al. ${ }^{18}$

The most important observation of the study was the identification of $10(15.87 \%)$ potential GDM women who were negative as per OGCT criteria and were not even required to go in for the subsequent OGTT confirmation.

Table 4: Comparison of various criteria for diagnosis of GDM

Definition of GDM by different criteria

\begin{tabular}{|c|c|c|c|c|c|}
\hline Criteria & Method & $\begin{array}{l}\text { Fast } \\
\text {-ing } \\
\text { (mg/ } \\
\text { dl) }\end{array}$ & $\begin{array}{l}1 \mathrm{hr} \\
\text { (mg/ } \\
\text { dl) }\end{array}$ & $\begin{array}{l}2 \mathrm{hr} \\
\text { (mg/ } \\
\text { dl) }\end{array}$ & $\begin{array}{l}3 \mathrm{hr} \\
\text { (mg/ } \\
\text { dl) }\end{array}$ \\
\hline WHO & $\begin{array}{l}\text { Fasting } 75 \\
\text { g OGTT }\end{array}$ & $\geq 126$ & - & $\geq 140$ & - \\
\hline IADPSG & $\begin{array}{l}\text { Fasting } 75 \\
\text { g OGTT }\end{array}$ & $\geq 92$ & $\geq 180$ & $\geq 153$ & - \\
\hline DIPSI & $\begin{array}{l}\text { Non } \\
\text { fasting } 75 \\
\text { g OGTT }\end{array}$ & - & - & $\geq 140$ & - \\
\hline ADA & $\begin{array}{l}\text { Fasting } \\
100 \mathrm{~g} \\
\text { OGTT }\end{array}$ & 95 & 180 & 155 & 140 \\
\hline
\end{tabular}

GDM: Gestational Diabetes Mellitus; WHO: World Health Organisation; ADA: American Diabetes Association; IADPSG: International Association of Diabetes and Pregnancy Study Groups; DIPSI: Diabetes In Pregnancy Study Group in India; OGTT: Oral Glucose Tolerance Test

Mohan $\mathrm{V}$ et al concluded in their study that, current DIPSI guidelines of a single non-fasting OGTT using 2 hr cut-off point of $140 \mathrm{mg} / \mathrm{dl}$ would miss $72.3 \%$ of women with GDM diagnosed by WHO criteria. ${ }^{19}$

Brazilian Gestational Diabetes Study Group evaluated the ADA \& WHO diagnostic criteria against pregnancy outcomes in an observational study of nearly 5000 women and found that WHO criteria identified more cases of GDM compared to $\operatorname{ADA}(7.2 \%$ vs $2.4 \%) .{ }^{20}$
Schmidt et al found that the diagnostic pick up rate in their study on GDM was three times more with the WHO criteria than ADA criteria. They also detected increased rate of morbidity in women diagnosed as GDM by WHO criteria. They documented an important observation that the subjects with GDM by WHO criteria delivered macrosomic infants. ${ }^{20}$

ADA criteria were originally validated against the future risk of maternal diabetes and not based on adverse perinatal outcome ${ }^{21}$. WHO testing for glucose tolerance during pregnancy was abnormal in the greater percentage of women with adverse outcome than the cumbersome two step ADA test in a study by Pettitt DJ et al. ${ }^{22}$

Fasting glucose tends to have low sensitivity in South Asians. Hence 2 hour Postprandial Glucose is more sensitive than Fasting glucose in diagnosing GDM in Indians. ${ }^{23,24}$

Further, assuming that the effective treatment is available, WHO criteria of 2 hour Postprandial Glucose $\geq$ $140 \mathrm{mg} / \mathrm{dl}$ identifying a large number of case may have a greater potential for prevention which has been confirmed by Meltzer et al. ${ }^{25}$

Treatment of Gestational diabetes mellitus as defined by WHO criteria has reduced serious perinatal morbidity and improved the woman's health related quality of life. ${ }^{10,11}$

The two step procedure of screening with $50 \mathrm{~g}$ GCT and then diagnosing GDM based on the cut off values with $100 \mathrm{~g}$ or $75 \mathrm{~g}$ OGTT is not practical as the pregnant women have to visit the antenatal clinic at least twice and the number of blood samples drawn varies from 3 to 5 which women resent. ${ }^{21}$

The recent IADPSG criteria, although adopted recently by a WHO expert group, may be difficult to adopt in developing countries due to shortage of trained phlebotomists, extra costs and the lack of laboratory. ${ }^{19}$

Studies from the Western countries state that the use of IADPSG criteria would lead to inflated rates of GDM. ${ }^{26-}$ 28

It is reasonable to assume that since the IADPSG has raised the 2 -h value to $153 \mathrm{mg} / \mathrm{dl}$, many cases of GDM could be missed.

WHO criteria of $>140 \mathrm{mg} / \mathrm{dl}$ alone appears to be sufficient to diagnose GDM, as it picks up the majority of GDM cases diagnosed by both the whole WHO criteria as well as the same number of cases as the three sample

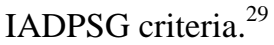

\section{Prevalence of GDM:}

Prevalence rates are found to be higher in black Hispanic, Latino, Native American and Asian women compared to 
Caucasians. Yue et al, in an Australian study, reported a higher relative risk in Indian women $(17 \%)$ as compared to $3 \%, 10 \%$ and $15 \%$ in Anglo-Celtic, Aboriginal and Chinese inhabitants respectively. ${ }^{30}$

Increasing trend in prevalence rates has been documented in different regions of the country. The prevalence of Gestational diabetes mellitus in our study was $6.3 \%$. This is comparable to $6.0 \%, 6.6 \%$ and $6.7 \%$ prevalence rates of study of Nilofer AR et $\mathrm{al}^{31}$, Kalra $\mathrm{P}$ et $\mathrm{al}^{32}$ and Verma et $\mathrm{al}^{33}$ respectively.

\section{CONCLUSIONS}

For universal screening, we suggest a single fasting OGTT with a 75 gram of oral glucose load and diagnosing women with 2 hour $\mathrm{PPG} \geq 140 \mathrm{mg} / \mathrm{dl}$ as GDM. This method, recommended by WHO serves both as a one-step screening and diagnostic procedure and is easy to perform besides being economical.

\section{Funding: No funding sources}

Conflict of interest: None declared

Ethical approval: Approved by Ethical Committee

\section{REFERENCES}

1. Anjana RM, Pradeepa R, Deepa M, Datta M, Sudha V, Unnikrishnan R, et al. Prevalence of diabetes and prediabetes (impaired fasting glucose and/ or impaired glucose tolerance) in urban and rural India :Phase I results of the Indian Council of Medical Research -INdia DIAbetes (ICMR-INDIAB)Study. Diabetologia. 2011;54(12): 3022-7.

2. Metzger, Boyd E, Coustan DR. Summary and recommendations of the fourth international workshop-conference on gestational diabetes mellitus: the organising committee. Diabetes Care. 1998;21 (Suppl 2):B161-7.

3. Raja MW, Baba TA, Hanga AJ, Bilquees S, Rasheed ,Haq IU, et al. A study to estimate the prevalence of gestational diabetes mellitus in an urban block of Kashmir valley (North India). Int J Med Sci Public Health. 2014;3:191-5.

4. Gopalakrishnan V, Singh R, Pradeep Y, Kapoor D, Rani AK, Pradhan S, Yadav SB, et al. Evaluation of the prevalence of gestational diabetes mellitus in North Indians using the International Association of Diabetes and Pregnancy Study groups (IADPSG) criteria. J Postgrad Med. 2015;61(3):155-8.

5. Jindal R, Siddiqui MA, Gupta N, Wangnoo SK. Prevalence of glucose intolerance at 6 weeks postpartum in Indian women with gestational diabetes mellitus. Diabetes Metab Syndr. 2015;9:143-6.

6. Damm P. Future risk of diabetes in mother and child after gestational diabetes. Int $\mathrm{J}$ Gynaecol Obstet 2009;104:25-6.

7. HAPO Study Co-operative Research group. Metzger BE, Lowe LP, Dyer AR, Trimble ER, Chaovarindr
$\mathrm{U}$, et al. Hyperglycaemia and adverse pregnancy outcomes. N Engl J Med. 2008;358:1991-2002.

8. Dornhorst A, Paterson CM, Nicholls JS, Wadsworth J, Chiu DC, Elkeles RS, et al. High prevalence of gestational diabetes in women from ethnic minority groups. Diabet Med. 1992;9:820-5.

9. Cosson E. Screening and insulin sensitivity in gestational diabetes. Abstract volume of the 40th annual meeting of the EASD. 2004; A 350.

10. Crowther CA, Hiller JE, Moss JR, McPhee AJ, Jeffries WS, Robinson JS, et al. Effect of treatment of gestational diabetes mellitus. N Engl J Med. 2005; 352:2477-86.

11. Gayle C, Germain S, Marsh MS, Rajasingham D, Brackenridge A, Carroll $\mathrm{P}$, et al. Comparing pregnancy outcomes for intensive versus routine antenatal treatment of a GDM based on a $75 \mathrm{gm}$ OGTT 2- $\mathrm{h}$ blood glucose (>140mg/dl). Diabetologia. 2010; 53:S435.

12. Magon N. Gestational diabetes mellitus: Get, set, go. From diabetes capital of the world to diabetes care capital of the world. Indian $\mathbf{J}$ Endocr Metab. 2011;15:161-9.

13. Ferrara A, Kahn HS, Quesenberry CP, Riley C, Hedderson MM. An increase in the incidence of gestational diabetes mellitus: Northern California, 1991-2000. Obstet Gynecol. 2004;103:526-533.

14. Reiher H, Fuhramann K, Noack S, Woltanski KP, Jutzi E, Hahn von Dorsche H, et al. Age dependent insulin secretion of the endocrine pancreas in vitro from foetuses of diabetic and non-diabetic patients. Diabetes Care. 1983;6:446-51

15. Nahum GG, Wilson SB, Stanislaw H. Earlypregnancy glucose screening for gestational diabetes mellitus. J Reprod Med. 2002;47:656-62.

16. Huynh J, Ratnaike S, Bartalotta C, Permezel M, Houlihan $\mathrm{C}$, et al. Challenging the glucose challenge test. Aust N Z J Obstet Gynaecol. 2011;51(1): 22-25.

17. Das V, Kamra S, Mishra A. Screening for gestational diabetes and maternal and foetal outcome. J Oster Gynecol India. 2004;54:449-51.

18. Seshiah V, Balaji V, Balaji MS et al. Gestational diabetes mellitus in India. J Assoc Physicians India. 2004;52:707-11.

19. Mohan V, Mahalakshmi MM, Bhavadharini B, Maheshwari K, Kalaiyarasi G, Anjana RM, et al. Comparison of screening for gestational diabetes mellitus by oral glucose tolerance tests done in nonfasting(random) and fasting states. Acta Diabetol. 2014;51:1007-13.

20. Schmidt MI, Duncan BB, Reichelt AJ, Branchtein L, Matos M C, Costa e Forti A, Yamashita T, et al. Brazilian Gestational Diabetes Study Group. Gestational diabetes mellitus diagnosed with a 2-h $75-\mathrm{g}$ oral glucose tolerance test and adverse pregnancy outcomes. Diabetes care. 2001;24:11511155.

21. Seshiah V, Balaji V, Balaji MS, Sekar A, Sanjeevi $\mathrm{CB}$ et al. One step procedure for screening and 
diagnosis of gestational diabetes mellitus. J Obstet Gynecol India. 2005;55:525-29

22. Pettitt DJ, Bennett PH, Hanson RL, et al. Comparison of World Health Organization and National Diabetes Data Group procedures to detect abnormalities of glucose tolerance during pregnancy. Diabetes Care. 1994;17:1264-8.

23. Zhu WW, Fan L, Yang HX, Kong LY, Su SP, Wang ZL, Hu YL, Zhang MH, Sun LZ, Mi Y, Du XP, Zhang $\mathrm{H}$, Wang YH ,Huang YP, Zhong LR ,Wu HR, Li N ,Wang YF, Kapur A. Fasting plasma glucose at 24-28 weeks to screen for gestational diabetes mellitus: new evidence from China. Diabetes Care. 2013;36:12038-2040.

24. Balaji V, Balaji M, Anjanakshi C, Cynthia A, Arthi $\mathrm{T}$, Seshaiah V. Inadequacy of fasting plasma glucose to diagnose gestational diabetes mellitus in Asian Indian Women. Diabetes Res Clin Pract. 2011;94:e21-e23.

25. Meltzer SJ, Synder J, Morin L, et al. Validation of normative data for $75 \mathrm{~g}$ oral glucose tolerance test (OGTT) in a Montreal pregnant population considering ethnicity. In: Matsdinsky FM (ed). Abstract book of the 64th Scientific Sessions of the American Diabetes Association, Florida. American Diabetes Association. 2004; A19.

26. Kendrick JM. Screening and diagnosing gestational diabetes mellitus revisited: implications from HAPO. J Perinat Neonatal Nurs. 2011;25:226-32

27. Bodmer-Roy S, Morin L, Cousineau J, Rey E. Pregnancy outcomes in women with and without gestational diabetes mellitus according to the International Association of Diabetes and Pregnancy Study Groups criteria. Obstet Gynecol. 2012;120:746-52.
28. Reyes-Munoz E, Parra A, Castillo-Mora, OrtegaGonzalez C, et al. Effect of the diagnostic criteria of the international association of diabetes and pregnancy groups on the prevalence of gestational diabetes in urban Mexican women: A cross-sectional study. Endocr Pract. 2012; 18:146-151.

29. Nallaperumal S, Bhavadharini B, Mahalakshmi MM, Maheswari K, Jalaja R, Moses A, Mohan Vet al . Comparison of the world health organization and the International association of diabetes and pregnancy study groups criteria in diagnosing gestational diabetes mellitus in South Indians. Indian J Endocr Metab. 2013;17:906-9.

30. Yue DK, Molyneaux LM, Ross GP, Constantino MI, Child AG, Turtle JR. Why does ethnicity affect prevalence of gestational diabetes mellitus? The underwater volcano theory. Diabet Med. 1996;13:748-52.

31. Nilofer AR, Raju VS, Dakshayini BR, Zaki SA. Screening in high risk group of gestational diabetes mellitus with its maternal and fetal outcomes. Indian J Endocr Metab. 2012;16:S74-8.

32. Kalra P, Kachhwaha CP, Singh HV. Prevalence of Gestational Diabetes Mellitus and its outcome in western Rajasthan. Indian J Endocr Metab. 2013; 17:677-80.

33. Verma AK, Singh B, Mengi V. Gestational diabetes in rural women of Jammu. Indian J Community Med 2008;33:54-5

Cite this article as: Puttaraju CM, Eti M. WHO 75 gram OGTT-A single step procedure for screening and diagnosis of Gestational Diabetes Mellitus. Int J Reprod Contracept Obstet Gynecol 2015;4:2022-7. 